\title{
Internal Lateral Sphincterotomy in Yaounde: Comparative Short-Term Results of Open versus Closed Techniques
}

\author{
Georges Bwelle Motto',2, Yannick Mahamat Ekani Boukar'3, Guy Aristide Bang1, \\ Joseph Cyrille Chopkeng Ngoumfe ${ }^{2 *}$, Fabrice Tientcheu Tim², Arthur Essomba ${ }^{1,2}$, \\ Maurice Aurélien Sosso ${ }^{1}$
}

\author{
${ }^{1}$ Department of Surgery and Specialties, Faculty of Medicine and Biomedical Sciences, The University of Yaoundé I, \\ Yaounde, Cameroon \\ ${ }^{2}$ Department of Visceral and Digestive Surgery, Yaoundé Central Hospital, Yaounde, Cameroon \\ ${ }^{3}$ Department of Surgery, University of Buea, Buea, Cameroon \\ Email: gbwelle@gmail.com, boukaryoussouf@gmail.com, guyaristidebang@yahoo.fr, *chopkeng.c@gmail.com, \\ timfabrice2002@gmail.com, artgessomba@gmail.com, sossomaurice@yahoo.fr
}

How to cite this paper: Bwelle Motto, B., Ekani Boukar, Y.M., Bang, G.A., Chopkeng Ngoumfe, J.C., Tientcheu Tim, F., Essomba, A. and Sosso, M.A. (2021) Internal Lateral Sphincterotomy in Yaounde: Comparative Short-Term Results of Open versus Closed Techniques. Surgical Science, 12, 374-380. https://doi.org/10.4236/ss.2021.1211039

Received: October 5, 2021

Accepted: November 26, 2021

Published: November 29, 2021

Copyright $\odot 2021$ by author(s) and Scientific Research Publishing Inc. This work is licensed under the Creative Commons Attribution International License (CC BY 4.0).

http://creativecommons.org/licenses/by/4.0/

\section{Open Access}

\begin{abstract}
Background: Chronic anal fissure is a benign disorder which is associated with considerable discomfort. Aim of the Work: The aim of this study was to compare the post-operative results of open and closed internal lateral sphincterotomies in the short and medium term. Patient and Methods: We carried out a prospective randomized comparative study in the digestive and visceral surgery departments of Central Hospital of Yaounde over a period of 15 months. Patients were evaluated for each technique by several variables, including duration of surgery, post-operative pain, recurrence, surgical wound infection, gas and/or stool incontinence, and healing time with follow-up up to 12 months postoperatively. Results: A total of 63 patients underwent surgery within them we had 32 open lateral internal sphincterotomies (group 1) and 31 closed lateral internal sphincterotomies (group 2). There were 35 men and 28 women with a sex ratio of 1.25 . The mean age was $35.36 \pm 10.16$ years with extremes ranging from 19 to 62 years. The typical presentation was pain on defecation. The majority of fissures were located at the posterior commissure. The average duration of the procedure was longer in patients in group 1 (15.34 minutes) compared to 5.22 minutes in patients in group 2 . We found $3.12 \%$ of surgical wound infections in patients in group 1 and neither patient in group 2. Gas incontinence was $6.45 \%$ in group 2 patients and $28.12 \%$ in group 1 . The mean intensity of pain at 24 hours post-operative was between 4 and 6 on the visual analogue scale in patients in group 2 and between 7 and 10 in group 1. Wound healing time was 8.9 days in group 1 and 4 days in
\end{abstract}


group 2 patients. The hospital stay was 24 hours for both groups of patients. No recurrence was noted during the 6-month follow-up period. Conclusion: Closed lateral internal anal sphincterotomy is the treatment of choice for chronic anal fissures because it is effective and associated with a lower complication rate than the open sphincterotomy technique.

\section{Keywords}

Anal Fissure, Internal Lateral Sphincterotomy, Open Technique, Close Technique

\section{Introduction}

Anal fissure is an ulceration of the anoderm of the anal canal [1]. It is an embarrassing pathology known to mankind since antiquity, and despite its strong impact on the quality of life; it is relatively tolerated by patients [1]. Multiple authors in the West have agreed for years on better post-operative results with closed internal lateral sphincterotomy [2] [3]. In Cameroon, open internal lateral sphincterotomy has been practiced for a long and we, therefore, set out to evaluate the results of the two techniques in our settings.

\section{Methodology}

This was a prospective randomized study, conducted at the Yaounde Central Hospital (YCH) over a period of 15 months.

The sampling was consecutive and we included adult patients operated for chronic anal fissure without other associated anorectal pathologies. Patients with comorbidities that could influence the healing process were excluded.

The allocation of patients to groups was done in an alternative way.

All patients were operated on by a proctologic surgeon. The technique used was a lateral leiomyotomy of the internal sphincter. The open technique was that described by Parks [4]: a vertical anocutaneous incision of about $1.5 \mathrm{~cm}$ was made on the left lateral border, the internal sphincter was dissected, exposed and sectioned to the pectineal line. The closed technique was that described by Goligher [5]. It was done without anocutaneous incision: the flat of the scalpel was introduced into the inter-sphincter space, the blade rotated by $90^{\circ}$, resulting in a section of the internal sphincter down to the mucosa.

The patient resumed oral feeding rich in dietary fiber on the same day after the operation. Laxatives (paraffin oil), analgesics (paracetamol), and anti-inflammatory drugs with a proton pump inhibitor (omeprazole) were prescribed for two to three weeks.

The variables investigated were: socio-demographic data (age, gender, occupation), clinical data (symptomatology, location of the fissure) and postoperative data for complications of these procedures (pain, infections, abscess formation, incontinence, oozing, recurrence and healing time). Follow-up was done every 
two days a week, then once a week for a month, twice a month for one month and once every month for six months.

Data were recorded using CS Pro version 7 software and analyzed using IBM SPSS (Statistical Package of Social Sciences) version 23.0. Qualitative data were expressed as headcount and percentage; illustrated in tables and figures. Chisquare and Fischer tests were used to test for association between categorical values; while the student's t test was used to compare means. The alpha risk was set at $5 \%$, with a statistical significance of $\mathrm{p} \leq 0.05$.

Ethical clearance was obtained from the Research and Ethics Committee of the Faculty of Medicine and Pharmaceutical Sciences, University of Douala. Study authorization was obtained from the administrative services of the $\mathrm{YCH}$.

\section{Results}

During our study we collected 63 patients. 31 had a closed anal sphincterotomy and $32 \mathrm{had}$ an open anal sphincterotomy. There were 35 males and 28 females, with a sex ratio of 1.25 . The mean age was $35.36 \pm 10.16$ years with extremes ranging from 19 to 62 years. Anal pain was the main reason for consultation and was present in all patients, followed by anal bleeding with $49.20 \%$ of cases. The majority of the fissures were located on the posterior commissure, accounting for $77.77 \%$ of cases. Table 1 shows the different locations of the fissures.

All patients were operated under locoregional spinal anaesthesia. The average operating time was 15.34 minutes for open sphincterotomy and 5.22 minutes for closed sphincterotomy $(\mathrm{p}=0.001)$.

Postoperative pain between 4 and 6 on the visual analogue scale (VAS) in patients with closed sphincterotomy had completely disappeared by the third week. Postoperative pain between 7 and 10 in patients with open sphincterotomy had completely disappeared by the 4 th week.

The average healing time was 8.9 days for the open technique and 4.2 days for the closed technique $(\mathrm{p}=0.001)$.

Gas intolerance was present in $6.45 \%$ of patients operated on by the closed technique. It disappeared after 1 week. No incontinence to liquid stools was present in these patients. In the patients operated on by the open technique, gas incontinence was present in $28.12 \%$ of cases up to the 1 st week and in $9.37 \%$ of cases up to the 2 nd week. Liquid stool incontinence was present in $6.25 \%$ of these patients until the first week.

Table 1. Locations of anal fissures.

\begin{tabular}{ccc}
\hline Location of anal fissure & N & Percent (\%) \\
\hline Posterior commissure & 49 & 77.77 \\
Anterior commissure & 9 & 14.28 \\
Both commissures & 3 & 4.76 \\
Paracommissural & 2 & 3.17 \\
Total & 63 & 100 \\
\hline
\end{tabular}


The hospital stays for both techniques was 24 hours. The postoperative course for each technique is shown in Table 2.

\section{Discussion}

In this study, we compared the results of open and closed lateral sphincterotomy techniques.

We recruited 63 subjects divided into two groups; 32 patients who underwent open sphincterotomy (group 1) and 31 who underwent closed sphincterotomy (group 2). The mean age was 35.36 years. This result is similar to that of Fall et al. in Dakar in 2002 [6] who had a mean age of 38 years. Garcia et al. [7] found an average age of 49.5 years due to the relatively older population. Anal fissure disease is therefore the prerogative of young adults between 35 and 50 years of age.

Anal pain and bleeding in the stool were the most common symptoms found in this study. These results are similar to those found in the literature [8] [9]. The pain was triggered by the passage of faeces, subsided for some time after the stool, and then resumed for several hours (4 - 6 hours).

The posterior commissural location was the most common with $81.10 \%$ of cases. Siproudhis et al. in France in 2008 [8] found a similar result with $90.00 \%$ of posterior commissural location for a sample of 85 cases. This usual location of the fissure is explained by a lack of vascularisation of the posterior commissural of the anal canal, which has been well demonstrated in anatomical, angiometric and debimetric studies [8] [9].

The shorter operation time in group 2 patients (5.22 minutes) compared to group 1 patients (15.35 minutes) was a consequence of the smaller number of surgical steps in group 2 patients. Indeed, in these patients no incision of the

Table 2. Surgical follow-up according to the technique used.

\begin{tabular}{lccc}
\hline \multicolumn{1}{c}{ Complications } & $\begin{array}{c}\text { Open } \\
\text { sphincterotomy }\end{array}$ & $\begin{array}{c}\text { Closed } \\
\text { sphincterotomy }\end{array}$ & P value \\
\hline Duration intervention (min) & 15.34 & 5.22 & $<0.001$ \\
Infection N (\%) & $1(3.12)$ & $0(0.00 \%)$ & 0.492 \\
Hemorrhage N (\%) & $1(3.12)$ & $0(0.00 \%)$ & 0.746 \\
Length of hospital stay (hours) & 24 & 24 & 0.001 \\
Gas Incontinence N (\%) & $9(28.12)$ & $2(6.45)$ & $<0.001$ \\
Liquid stool Incontinence & $2(6.25)$ & 0 & 0.005 \\
N (\%) & 8.9 & 4 & $<0.001$ \\
Wound healing time (days) & $0(0.00 \%)$ & $0(0.00 \%)$ & \\
Anal stenosis & $0(0.00 \%)$ & $0(0.00 \%)$ & \\
Recurrences & $0(0.00 \%)$ & $0(0.00 \%)$ & \\
Deaths & & & \\
\hline
\end{tabular}


anoderm was made and therefore no suturing of the surgical wound.

We found $3.12 \%$ and $0.00 \%$ of postoperative infections in patients in group 1 and 2 respectively. These results are similar to those of D. Patel et al. in India in 2011 [10] who found $2 \%$ and $0.00 \%$ infection in patients with open and closed technique respectively. H. Shankarlal et al. in India [11] found $10.3 \%$ infection in open sphincterotomy and $4.2 \%$ in closed sphincterotomy with a larger sample size. Infection was always higher in the open technique for all authors.

Patients in group 1 had more postoperative pain and of longer duration than patients in group 2 . We found that the average postoperative pain at 24 hours according to the VAS was between 7 and 10 for open sphincterotomies and between 4 and 6 for closed sphincterotomies. This pain disappeared in 4 weeks for the open technique and in 3 weeks for the closed technique. This could be explained by a more extensive inflammatory process in patients who had an incision and suture of the anoderm [2].

The hospital stay was 24 hours in both groups of patients as in all authors [12] [13].

Gas incontinence was present in $9.37 \%$ of patients in group 1, controlled in 2 weeks and in $6.45 \%$ of patients in group 2, controlled in 1 week. Liquid stool incontinence was found only in group 1 patients at $3.70 \%$ and was controlled in 1 week. Sanabani et al. [13] in Egypt found $6.7 \%$ and $0.00 \%$ for gas incontinence respectively for open and closed techniques as well as $5 \%$ and $0.00 \%$ for liquid stool incontinence. Indeed, during open sphincterotomy, in addition to the sphincter section, the incision of the mucosa would play a role in continence. The mucosa of the anal canal and the intermediate zone is rich in sensory nerve endings allowing a fine and discriminating analysis of the rectal contents (gas, liquid, solid) [14].

The difference in wound healing time was statistically significant between patients in the two groups $(\mathrm{p}=0.001) ; 8.9$ days for those in group 1 and 4 days for those in group 2. This difference could be explained by the fact that patients in group 1 had an incision and then closure of the anoderm with non-absorbable suture which was removed between 8 and 10 days. No recurrence was recorded in either group during the 12-month follow-up period.

The limitations of our study are the monocentric nature and the short follow-up time. A multicentric study with a longer follow-up period would allow a better evaluation of these two techniques and their recurrence rates.

\section{Conclusion}

Open and closed internal lateral anal sphincterotomy are significantly different in terms of short and medium term post-operative outcomes. Closed internal lateral anal sphincterotomy would be the treatment of choice for chronic anal fissures because it is effective and associated with a lower complication rate than the open sphincterotomy technique, the latter being more indicated in case of anal fissure associated with the haemorrhoidal disease. 


\section{Authors' Contributions}

GBM and YMEB: Study design.

JCCN: Data collection.

JCCN and TFT: Data analysis.

GBM, JCCN: Drafting the manuscript.

GAB, YBEM, TFT: Proofreading and editing the manuscript.

AE: Final revision of the manuscript.

MAS: Final Approval for submission.

\section{Conflicts of Interest}

The authors declare no conflict of interest.

\section{References}

[1] Beaty, J.S. and Shashidharan, M. (2016) Anal Fissure. Clinics in Colon and Rectal Surgery, 29, 30-37.

[2] Gupta, V., Rodrigues, G., Prabhu, R. and Ravi, C. (2014) Open Versus Closed Lateral Internal Anal Sphincterotomy in the Management of Chronic anal Fissures: A Prospective Randomized Study. Asian Journal of Surgery, 37, 178-183. https://doi.org/10.1016/j.asjsur.2014.01.009

[3] Ghayas, N., Younus, S.M., Mirani, A.J., Ghayasuddin, M., Qazi, A., Suchdev, S.D., et al. (2015) Frequency of Post-Operative Faecal Incontinence in Patients with Closed and Open Internal Anal Sphincterotomy. Journal of Ayub Medical College Abbottabad, 27, 878-882.

[4] Parks, A.G. (1967) The Management of the Fissure in Ano. Journal of Hospital Medicine, 1, 737-738.

[5] Hoffman, D.C. and Goligher, J.C. (1970) Lateral Subcutaneous Internal Sphincterotomy in Treatment of Anal Fissure. British Medical Journal, 3, 673-675.

https://doi.org/10.1136/bmj.3.5724.673

[6] Fall, B., Diao, B., Mbengué, M. and N'diaye, A. (2002) Prise en charge des fissures anales chronique: A propos de 31 cas. Dakar Medical, 164-167.

[7] García-Granero, E., Sanahuja, A., García-Botello, S.A., Faiz, O., Esclápez, P., Espí, A., Flor, B., Minguez, M. and Lledó, S. (2009) The Ideal Lateral International Sphincterotomy (LIS): Clinical and Endosonographic Evaluation Following Open and Closed Internal and Sphincterotomy. Colorectal Disease, 11, 502-507.

https://doi.org/10.1111/j.1463-1318.2008.01645.x

[8] Pigot, F., Siproudhis, L. and Albert, F.A. (2005) Risks Factors Associated with Hemorroidal Symptoms in Specialized Consultation. Gastroentérologie Clinique et Biologique, 9, 237-245.

[9] Ellen, N., Okiémy, G., Koutaba, E. and Chocolat, R., Miabahou, M., Ibamba, A., et al. (2003) Traitement chirurgical des fissures anales au CHU de Brazza à propos de 21 cas. Journal Africain de Chirurgie Digestive, 2292-2295.

[10] Patel, S.D., Oxenham, T. and. Praveen, B.V. (2011) Medium-Term Results of Anal Advancement Flap Compared with Lateral Sphincterotomy for the Treatment of anal Fissure. International Journal of Colorectal Disease, 26, Article No. 1211. https://doi.org/10.1007/s00384-011-1234-4

[11] Patel, H.S., Chavda, J., Parikh, J. and Naik, N. (2013) Study of Operated Patients of 
Lateral Internal anal Sphincterotomy for Chronic anal Fissure. Journal of Clinical and Diagnostic Research, 7, 2863-2865.

https://doi.org/10.7860/JCDR/2013/7656.3698

[12] Coulibaly, B., Togola, B., Sissoko, F., Angoiba, N., Coulibaly, Y., Dembélé, M., Diallo, G., Diarra, B.M., Maiga, M.Y., Traoré, H.A., Dembele, K., Kalle, A. and Guindo, A. (1995) Etude epidemiologique de la pathologie anale au MALI = epidemiology of anal deseases in Mali. Médecine et chirurgie digestives, 24, 269-270.

[13] Al Sanabani, J., Al Salami, S. and Al Saadi, A. (2014) Closed Versus Open Lateral Internal Anal Sphincterotomy for Chronic anal Fissure in Female Patients. The Egyptian Journal of Surgery, 33, 178-181.

[14] Rullier, E., Laurent, C., Bretagnol, F., Rullier, A., Vendrely, V. and Zerbib, F. (2005) Sphincter-Saving Resection for All Rectal Carcinomas: The End of the 2-cm Distal Rule. Annals of Surgery, 241, 465-469.

https://doi.org/10.1097/01.sla.0000154551.06768.e1 